\section{Multiple, left ventricular cystic thrombi disappeared in 14 days 8}

A 50-year-old-man was admitted to our clinic with worsening dyspnea. Echocardiography revealed a dilated left ventricle (LV) with severely compromised systolic function and multiple mobile cystic masses (Video 1, Figs. 1a to 1c). These cystic masses were clearly observed with two-dimensional (2D) and three-dimensional (3D) transthoracic echocardiography (Video 2). A hydatid cyst was excluded with laboratory investigations. The treatment for acute heart failure was initiated based on guidelines. Weight-adjusted enoxaparin and warfarin were initiated. Thrombi started to resolve on the $5^{\text {th }}$ day and completely disappeared by the $14^{\text {th }}$ day of anticoagulation therapy (Fig. 1d). The patient was anticoagulated with warfarin (target international normalized ratio 2.5) for at least 3 months. During the follow-up, no embolic or hemorrhagic complications were observed.

Various examples of intracardiac cystic thrombi have been reported in the literature $(1,2)$. In one of the studies, LV cystic thrombus was reported to have disappeared on the $7^{\text {th }}$ day of treatment with warfarin and unfractionated heparin, similar to our case (2). With the widespread use of direct oral anticoagulants (DOAC) in clinical practice, examples of intracardiac thrombi resolution with

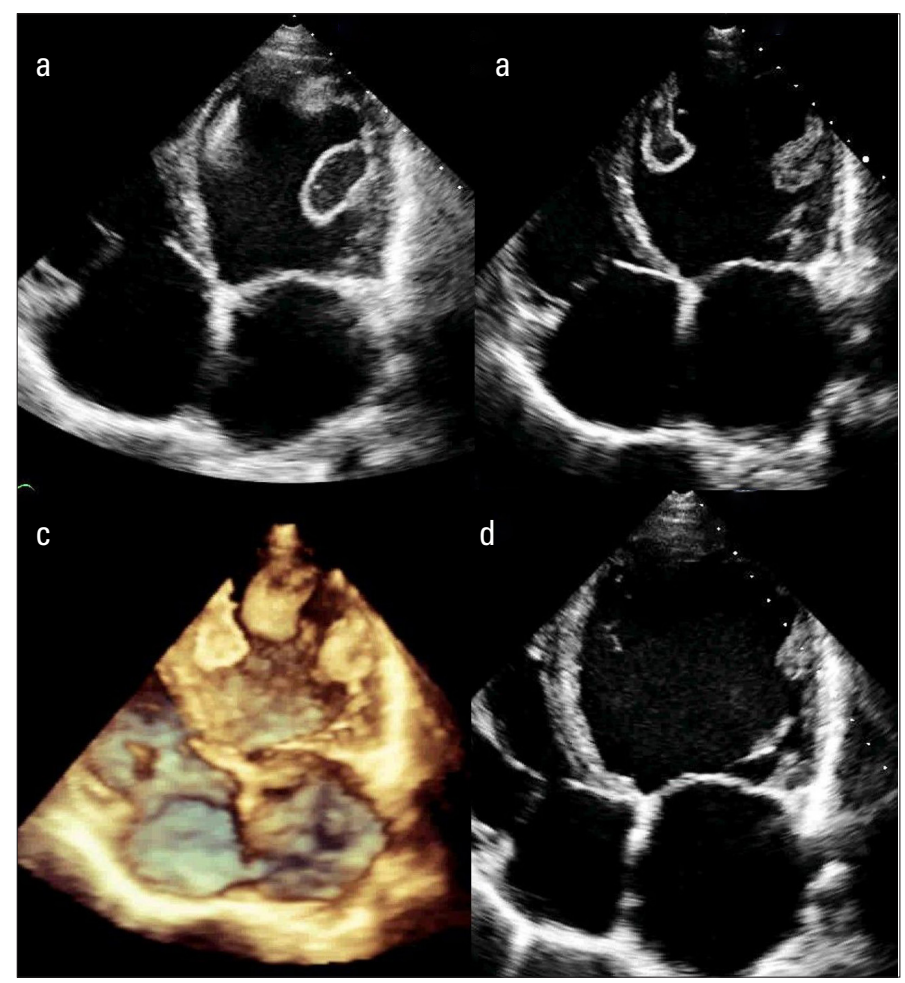

Figure 1. (a to c) There were three cystic thrombi in the left ventricle clearly seen with 2D and 3D transthoracic echocardiography. (d) Thrombi started to resolve on the $5^{\text {th }}$ day and completely disappeared by the $2^{\text {nd }}$ week of anticoagulation therapy
DOACs have been reported. For instance, intracardiac thrombus was resolved on the $13^{\text {th }}$ day with rivaroxaban $\left(15 \mathrm{mg} /\right.$ day) $(3)$, on the $16^{\text {th }}$ day with apixaban $(2 \times 5 \mathrm{mg} / \mathrm{day})(4)$, and on the $27^{\text {th }}$ day with dabigatran $(220 \mathrm{mg} /$ day) (5). Surgery may be considered, particularly for a large, protruding, and mobile thrombus. Differential diagnosis for blood cysts, hydatid cyst, and myxoma with central necrosis should be kept in mind. However, in our patient, the clinical course and response to anticoagulation confirmed the diagnosis of a thrombus with cystic appearance.

Informed consent: Written informed consent to publication was obtained from the patient.

Video 1. The apical four chamber view revealed three cystic thrombi in the left ventricle by $2 \mathrm{D}$ echocardiography

Video 2. The 3D transthoracic echocardiography revealed three cystic thrombi in the left ventricle

\section{References}

1. Ozlü MF, Ozcan $F$, Tüfekçioğlu 0 . Left ventricular apical cystic thrombus mimicking a hydatid cyst. Can J Cardiol 2009; 25: e266. [Crossref]

2. Bozkurt A, Cayli M, Acartürk E. Cyst-like thrombi in the left ventricle. Anatol J Cardiol 2001; 1: 114.

3. Nakasuka K, Ito S, Noda T, Hasuo T, Sekimoto S, Ohmori H, et al. Resolution of left ventricular thrombus secondary to tachycardiainduced heart failure with rivaroxaban. Case Rep Med 2014; 2014: 814524. [Crossref]

4. Kawakami T, Kobayakawa H, Ohno H, Tanaka N, Ishihara H. Resolution of left atrial appendage thrombus with apixaban. Thromb J 2013; 11: 26. [Crossref]

5. Nagamoto Y, Shiomi T, Matsuura T, Okahara A, Takegami K, Mine D, et al. Resolution of a left ventricular thrombus by the thrombolytic action of dabigatran. Heart Vessels 2014; 29: 560-2. [Crossref]
Lale Dinç Asarcıklı (D), Haluk Furkan Şahan1 (D),
Hilal Erken Pamukcu1 ${ }^{1}$, Hamza Sunman'1 (D)
Department of Cardiology, Dr. Siyami Ersek Cardiovascular and Thoracic Surgery Training and Research Hospital; İstanbul- Turkey
1Department of Cardiology, Ministry of Health Dışkapı Yıldırım Beyazit Training and Research Hospital; Ankara-Turkey

Address for Correspondence: Dr. Lale Dinç Asarcıklı,

İstanbul Dr. Siyami Ersek Göğüs ve Kalp Damar Cerrahisi

Eğitim ve Araştırma Hastanesi, Kardiyoloji Kliniği, İstanbul-Türkiye

Phone: +90 2165424444

E-mail: mdlaledinc@gmail.com

CCopyright 2021 by Turkish Society of Cardiology -

Available online at

www.anatoljcardiol.com

D0I:10.5152/AnatolJCardiol.2021.26796 